\title{
Investigation of mRNA quadruplex formation in Escherichia coli
}

\author{
Markus Wieland \& Jörg S Hartig \\ Department of Chemistry, Konstanz Research School Chemical Biology (KoRS-CB) and the Zukunftskolleg, University of Konstanz, Konstanz, Germany. \\ Correspondence should be addressed to J.S.H. (joerg.hartig@uni-konstanz.de).
}

\begin{abstract}
The protocol presented here allows for the investigation of the formation of unusual nucleic acid structures in the $5^{\prime}$-untranslated region (UTR) of bacteria by correlating gene expression levels to the in vitro stability of the respective structure. In particular, we describe the introduction of G-quadruplex forming sequences close to the ribosome-binding site (RBS) on the mRNA of a reporter gene and the subsequent read-out of the expression levels. Insertion of a stable secondary structure results in the cloaking of RBS and eventually reduced gene expression levels. The structures and stability of the introduced sequences are further characterized by circular dichroism (CD) spectroscopy and thermal melting experiments. The extent of inhibition is then correlated to the stability of the respective quadruplex structure, allowing judgement of whether factors other than thermodynamic stability affect the formation of a given quadruplex sequence in vivo. Measuring gene expression levels takes $2 \mathrm{~d}$ including cloning; $C D$ experiments take 5 hours per experiment.
\end{abstract}

\section{INTRODUCTION}

Quadruplex structures are formed by guanosine-rich nucleic acid sequences. The guanine nucleobases assemble in so-called tetrads; within a quadruplex several (usually two or three) of such tetrads are stacked to form a compact, four-stranded structure (see Fig. 1a,b). DNA quadruplexes have caught much attention, as they are suspected to have significant roles in modulating genetic processes, e.g., at the ends of chromosomes, the telomeres. In addition to the presence of four-stranded structures in telomeres, potential quadruplex-forming sequences have been found to be enriched in promoter and 5'-untranslated regions (UTRs) of certain classes of genes ${ }^{1,2}$. The evidence for the formation of such structures in vivo is strong ${ }^{3-6}$; however direct proof of formation of a distinct nucleic acid conformation in a living cell turns out to be challenging. However, Schaffitzel et al. $^{7}$ were able to generate antibodies specific against folded $\mathrm{G}$-quadruplexes and demonstrate that these antibodies co-localize with the telomeres in vivo. In a more direct approach, chemical probing with dimethyl sulphate (DMS) was used in vivo to identify a G-quadruplex in the c-myc promoter ${ }^{8}$. For this purpose, cells were incubated with DMS, which methylates nucleobases depending on the secondary structure they are involved in. After the isolation of nucleic acids methylation sites, they can be identified and conclusions concerning the secondary structure can be drawn.

Although many studies have dealt with the formation and consequences of DNA quadruplexes, little is known about the existence of four-stranded RNA sequences in vivo. RNA folds into equally stable quadruplex structures, preferring the all-parallel orientation of the participating strands (see Fig. 1b) ${ }^{9}$. Contrary to duplex DNA, cellular RNA is generated as a single strand. With this respect the formation of non-duplex secondary structures should be favored because of the absence of competition with duplex formation. On the other hand, only a few studies have so far addressed quadruplex folding and its consequences in cellular RNAs. Kurreck and co-workers have recently demonstrated that a quadruplex motif from $5^{\prime}$-UTR of the human ZIC-1 gene reduced the expression of a reporter gene in mammalian cells by interfering with translation initiation ${ }^{10}$. Balasubramanian showed similar inhibition of gene expression mediated by an RNA quadruplex forming in the $5^{\prime}$-UTR of NRAS (neuroplastoma RAS viral oncogene homolog) using an in vitro transcription/translation assay ${ }^{11}$. In addition, it has been shown that RNA quadruplex formation is able to mediate the attenuation of a viral transcript ${ }^{12}$.

In order to detect quadruplex formation in bacteria, we have envisioned a strategy that connects the formation of a higher-order RNA structure to changes of a reporter gene expression ${ }^{13}$. For this purpose, the potential quadruplex-forming sequence is positioned at a site crucial for translational initiation (see Fig. 1c,d). The correct positioning of the quadruplex-forming sequences is achieved by site directed mutagenesis, a versatile method to not only change single nucleotides but also to insert or replace longer stretches of nucleotides on a plasmid ${ }^{13-16}$. In bacteria, the $16 \mathrm{~S}$ rRNA as the main component of small ribosomal subunit interacts with a purine-rich stretch located $\sim 10$ nucleotides upstream of the AUG start codon ${ }^{17,18}$. This sequence is termed ShineDalgarno (SD) and is a part of the ribosome-binding site (see Fig. 2a). For efficient translation initiation the SD sequence needs to be single stranded. Hence, upon formation of a secondary structure involving the SD sequence, gene expression should be reduced because of an inefficient SSU/mRNA (small ribosomal subunit (SSU)/mRNA) interaction. Indeed, nature makes use of this possibility to modulate gene expression in certain temperature-responsive genetic regulators. These so-called RNA thermometers are characterized by RNA duplex structures involving the SD sequence that respond to increasing temperatures with increased expression ${ }^{19}$. In addition, many naturally occurring riboswitches are based on a ligand-dependent structural rearrangement of the SD sequence ${ }^{20}$.

In order to investigate the formation of a quadruplex structure of a given sequence, it needs to be incorporated into a reporter mRNA in a way that folding masks the SD sequence in a quadruplex loop, e.g., see Figure 2a,b. It is important to keep the SD sequence constant if several sequences should be compared as shown in Figure 2. The necessity to incorporate the SD purine stretch to the sequence of interest represents a limitation to the approach, as it brings certain sequence restrictions. On the other hand, using a series of different constructs as shown in Figure 2 allows for comparison of how different quadruplex features affect their in vivo stabilities. For example, it is known from thermal denaturation studies that short loops result in more stable DNA G-quadruplexes ${ }^{21}$ 
and unpublished results from our laboratory indicate that RNA G-quadruplexes behave similarly. In addition, structures composed of three tetrad stacks are more stable compared with two stacks ${ }^{2}$. Hence, a series of different quadruplex stabilities can be generated by combining both loop-length and number of stacked tetrads (see Fig. 2$)^{13}$. By determining the influence on gene expression we found that the in vivo formation correlated well with the relative stabilities of the different quadruplexes, as determined by thermal denaturation ${ }^{13}$.

The quantification of thermodynamic stabilities of used quadruplexes is carried out by thermal denaturation experiments ${ }^{22,23}$. In principle, both UV and circular dichroism (CD) detection of the thermally induced changes of the nucleic acid structures is possible. Our group prefers CD spectroscopy measurements ${ }^{13,24}$, as quadruplexes can show hyper and hypochromicity in temperaturedependent UV spectra depending on the quadruplex conformation or used wavelength, whereas in CD spectra the loss of secondary structure always results in a decrease of the signal, best followed by a wavelength of $263 \mathrm{~nm}$. However, thermal denaturation studies carried out by measuring change of UV absorbance at $295 \mathrm{~nm}$ works equally well, as shown by other groups ${ }^{10,11}$.

Application of the presented protocol to the study of secondary structures other than quadruplexes should also be possible. In principle, every structure different from single-stranded RNA could be investigated in vivo using this procedure, as long as the folding of the structure efficiently masks the SD interaction and the restriction of incorporating the SD sequence can be studied. Naturally occurring systems involving duplex formation, such as riboswitches and RNA thermometers, have already been mentioned above. In addition, triplex and other higher order structures in addition to quadruplexes could be designed to render the ribosome-binding site inaccessible and hence could be studied using the presented protocol.

\section{Experimental design}

Overview of protocol stages (for an overview of the procedure see Fig.3). The quadruplex forming sequences are cloned in the $5^{\prime}$-UTR of the bacterial reporter gene enhanced green fluorescent protein (eGFP) using site directed mutagenesis. In detail, the sequences that are to be incorporated into the $5^{\prime}$-UTR are attached $5^{\prime}$ of a primer pair sequence specific to the incorporation site. After amplification by PCR, the template plasmids without the incorporated sequences are removed by restriction enzyme digestion. Subsequently the PCR product is purified, ligated and eventually transformed into Escherichia coli. Successful cloning is validated by sequencing. The influence of the quadruplex-forming sequences on the reporter gene expression is monitored by measuring eGFP fluorescence levels of the outgrown $E$. coli cultures.

In addition to the experiments in $E$. coli the secondary structures of the quadruplex forming sequences are also characterized in vitro. In order to do this, synthetic RNAs with the corresponding sequences are ordered and their structural properties investigated by CD spectroscopy in combination with thermal denaturation studies.

Correlating the in vitro stability of RNA quadruplexes to the influence of the corresponding quadruplex-forming sequences on gene expression in bacteria allows judgement of whether factors other than thermodynamic stability affect the formation of a given quadruplex sequence in vivo.

Reporter gene vector (serves as PCR template). In principle, all reporter gene constructs containing a strong $\mathrm{SD}$ sequence can be used as readout for the formation of quadruplex sequences. a

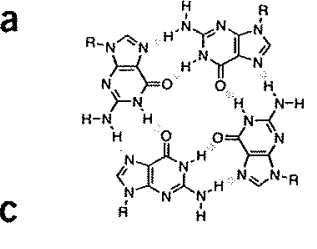

b

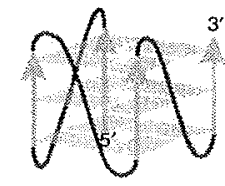

Initiation of

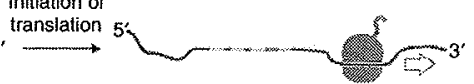

d

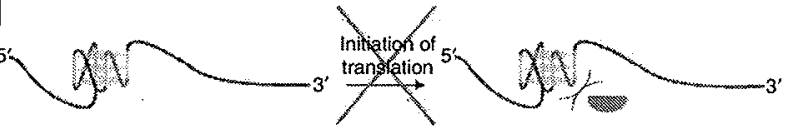

Figure 1 | General principle of investigating RNA quadruplex formation in bacteria by masking the Shine-Dalgarno (SD) sequence necessary for ribosomal initiation. (a) A tetrad is formed by four guanines. (b) Scheme of an RNA quadruplex structure with all strands in parallel orientation; within a quadruplex several (usually two or three) tetrads are stacked to form a compact, four-stranded structure. The blue arrows indicate the G-repeats. (c) Cartoon depicting the mRNA-based SD sequence (red) interacting with the $16 S$ rRNA of the small ribosomal subunit, resulting in initiation of translation. (d) Formation of the quadruplex structure (composed of four G-rich stretches shown in blue) results in the SD sequence incorporated into a loop of the four-stranded structure. In this conformation, SD is inaccessible and the initiation of translation is inhibited.

We used eGPF as the reporter gene, as its readout is very simple and does not require any processing of the cells.

Choice of $E$. coli strain. If the reporter gene is under the control of a T7 promoter, then the $E$. coli strain used for expression studies must have a T7 RNA polymerase encoded (e.g., E. coli BL21 (DE3) gold). Otherwise, all standard laboratory E. coli strains can be used for expression studies.

PCR primers. Primers bind at $5^{\prime}$ and $3^{\prime}$ of the insertion site. The sequence that needs to be inserted is attached at $5^{\prime}$ to one or (in case of long insertion sequences) to both primers. If primers are longer than 50 nucleotides, then they should be high performance liquid chromatography (HPLC) purified before cloning, in order to avoid mutations in the final construct caused by incomplete primer synthesis. For successful ligation during cloning one primer needs to be ordered 5 -phosphorylated during synthesis.

For the insertion of our constructs (see Fig. 2a,b), we used the following sequences with the introduced sequences underlined:

\begin{tabular}{lll}
\hline Construct & $\begin{array}{l}\text { Primer } \\
\text { name }\end{array}$ & Primer sequence \\
\hline $\mathrm{G}_{3} \mathrm{U}$ & $\mathrm{G}_{3} \mathrm{U}_{-} \mathrm{fW}$ & GGAGGGTGGGCATGGGCCATCATCATCATC \\
& $\mathrm{G}_{3} \mathrm{U}_{-} \mathrm{rv}$ & TTCCCACCCTTAAACAAAATTATTTCTAGAGGG \\
$\mathrm{G}_{3} \mathrm{U}_{2}$ & $\mathrm{G}_{3} \mathrm{U}_{2-} \mathrm{fW}$ & GGAGGGTTGGGATGGGCCATCATCATCATC \\
& $\mathrm{G}_{3} \mathrm{U}_{2--} \mathrm{rv}$ & ITCCCAACCCTAAACAAAATTATTTCTAGAGGG \\
$\mathrm{G}_{2} \mathrm{U}$ & $\mathrm{G}_{2} \mathrm{U}_{-} \mathrm{fW}$ & GGAGGTGGTTCATGGGCCATCATCATCATC \\
& $\mathrm{G}_{2} \mathrm{U}_{-} \mathrm{rv}$ & ITCCACCTTAAACAAAATTATTTCTAGAGGG \\
$\mathrm{G}_{2} \mathrm{U}_{2}$ & $\mathrm{G}_{2} \mathrm{U}_{2-} \mathrm{fW}$ & GGAGGTTGGTCATGGGCCATCATCATCATC \\
& $\mathrm{G}_{2} \mathrm{U}_{2-} \mathrm{rV}$ & ITCCAACCTTTAAACAAAATTATTTCTAGAGGG \\
\hline
\end{tabular}

PCR Primers can be stored at $-20^{\circ} \mathrm{C}$ for several months. 
RNA oligonucleotides. The sequences inserted upstream of the reporter gene are subsequently characterized in vitro by $\mathrm{CD}$ experiments. Consequently, the ordered RNA oligonucleotides should contain the complete structural relevant sequence used for in vivo studies (see Fig. 2a, underlined sequences are used for in vitro studies). The RNA oligonucleotides should be ordered HPLC purified for higher purity. The integrity and purity of the RNA oligonucleotide should be verified by polyacrylamide gel electrophoresis (PAGE) before using. They should be stored at $-20^{\circ} \mathrm{C}$ and can be kept for several months.

Thermal denaturation studies. In this protocol we describe thermal denaturation studies using $C D$ melting experiments measuring the change of CD signal at $263 \mathrm{~nm}$ in dependence to temperature changes. However, if no $C D$ spectrometer is available, it is also possible to determine thermal denaturation by measuring the absorption at $295 \mathrm{~nm}$ on a UV spectrometer.

Controls. It is crucial to check if the observed changes of gene expression levels are due to the formation of a quadruplex or entirely due to the introduction of additional nucleotides into the $5^{\prime}$-UTR. In order to exclude the latter it is necessary to also clone some constructs that have the same number of introduced nucleotides, but are unable to form a quadruplex. This can be achieved by changing a central guanosine of a G-repeat to a thymidine, and therefore destroying its capability to form a quadruplex. Also, the control sequence lacking the ability to form quadruplex should also be ordered as an RNA oligonucleotide and equally characterized by $\mathrm{CD}$ spectroscopy like the other sequences.

The in vivo eGFP expression is determined by measuring the fluorescence of the outgrown $E$. coli culture. In order to subtract background fluorescence levels of the medium it is necessary to measure the fluorescence of an outgrown $E$. coli culture that was not transformed with any plasmid, and thus does not express eGFP. a

$\begin{array}{ll}\text { wt } & \text { so } \\ \mathrm{G}_{3} \mathrm{U} & \text { UUGUUUAACUUUAAGAAGGAGAUAUACCAUGGGC } \\ \mathrm{G}_{3} \mathrm{U}_{2} & \text { UUGUUUAAGGGUGGGAAGGAGGGUGGGCAUGGGC } \\ \mathrm{G}_{2} \mathrm{U} & \text { UUGUUUAGGGUUGGGAAGGAGGGUUGGGAUGGGC } \\ \mathrm{G}_{2} \mathrm{U}_{2} & \text { UUGUUUAACUGGUGGAAGGAGGUGGUUCAUGGGC }\end{array}$

b
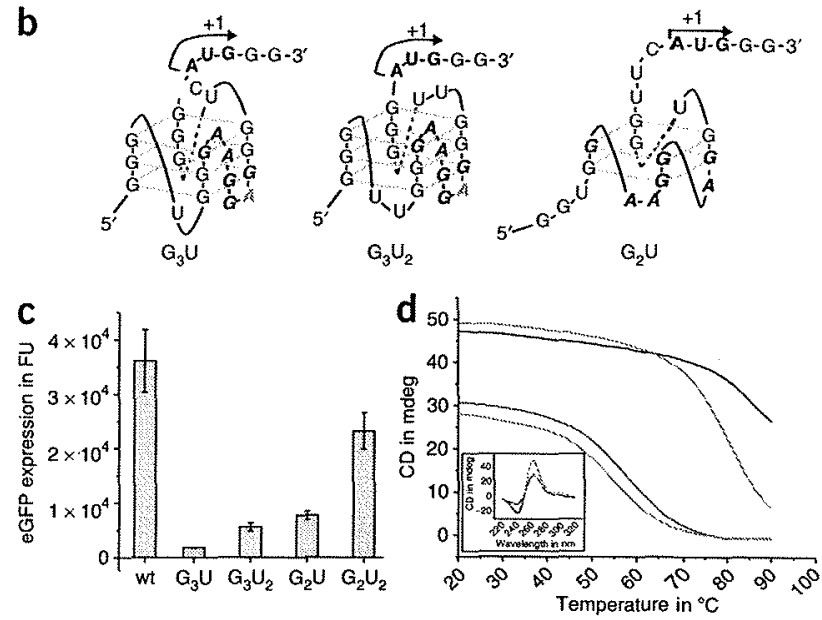

Figure 2 | Representative sequences and results. (a) Example sequences prone to fold into quadruplexes are shown; wt denotes the wild-type sequence; $G_{3} U, G_{3} U_{2}, G_{2} U, G_{2} U_{2}$ is an abbreviation for the proposed quadruplex fold of the inserted sequences. The underlined sequences are subsequently used for CD spectroscopy and thermal denaturation studies, red: SD sequence and blue: translation start codon. (b) Scheme showing likely folds of all-parallel RNA quadruplex sequences shown in a.

(c) Gene expression of constructs harboring the inserted sequences shown in a. (d) Circular dichroism (CD) and thermal denaturing studies of the underlined nucleotide sequences shown in a. CD spectra (insert) show that all investigated RNA quadruplexes fold into all-parallel conformations as shown in Figure $1 \mathrm{~b}$, as indicated by a minimum at $240 \mathrm{~nm}$ and a maximum at $265 \mathrm{~nm}$. Thermal denaturation studies (at $260 \mathrm{~nm}$ ) allow determination of the stabilities of the quadruplex structures. $C D$ spectrum and $C D$ therma denaturing studies of $G_{3} U$ is shown in black, $G_{3} U_{2}$ in red, $G_{2} U$ in blue and $\mathrm{G}_{2} \mathrm{U}_{2}$ in dark cyan. Modified with permission from reference 13 .

\section{MATERIALS}

\section{REAGENTS}

- 3 M Na-acetate, pH 5.2 (Merck, cat. no. 1.06267.1000)

- $6 \times$ agarose gel loading buffer (Fermentas, provided with GeneRuler)

- Agar (Roth, cat. no. 2266.2)

- Agarose (Roth, cat. no. 6352,2)

- Boric acid (Roth, cat. no. 5935.1)

- Carbenicilline (Roth, cat. no. 6344.3)

- DEPC (Roth, cat. no. K028.3)

- DNA oligonucleotides as primers for PCR (Metabion)

- DpnI (NEB, cat. no. R0176S)

- EDTA (Roth, cat. no. 8040.3)

- Electrocompetent $E$. coli (E. coli BL21(DE3) gold, Stratagene)

- Ethanol absolute (Sigma-Aldrich, cat. no. 32205)

- Ethidium bromide (Roth, cat. no. 2218.1) CAUTION Ethidium bromide

is toxic and mutagenic. Wear nitrile gloves when working with ethidium bromide all the time.

- GeneRuler 1-kb DNA ladder, ready-to-use (Fermentas, cat. no. SM0313)

- Glucose (Sigma, cat. no. D9434)

- HF buffer (provided with Phusion DNA polymerase)

- LB medium (Lennox) (Roth, cat. no. X964.1)

- $\mathrm{MgCl}_{2}$ (Acros, cat. no. 197530010)

- $\mathrm{MgSO}_{4}$ (Merck, cat. no. 1.05886)

- $\mathrm{NaCl}$ (VWR, cat. no. 27810.364)
- NEB buffer 4 (provided with DpnI)

- PCR template: eGFP expression vector (pet16b_eGFP, provided by AG

Scheffner, University of Konstanz)

- Phusion Hot Start DNA polymerase (NEB, cat. no. F540S)

- Qiagen Miniprep kit (Qiagen, cat. no. 27104)

- Quick Ligation kit (NEB, cat. no. M2200S)

- RNA oligonucleotides for CD spectra (Metabion)

- SOC medium (for recipe, see REAGENT SETUP)

- Tris Base (Sigma, cat. no. T1503)

- Tryptone (MP Biomedicals, cat. no. 1010817)

- Yeast extract (MP Biomedicals, cat. no. 194027)

- Zymo DNA Clean \& Concentrator (Zymo Research, cat. no. D4003)

- Zymoclean Gel DNA Recovery kit (Zymo Research, cat. no. D4001)

- EQUIPMENT

- Electroporation cuvette (Biorad, cat. no. 1652089)

- 15-mm Petri dishes (Peske, cat. no. 463-800)

- Razorblade type 22 (Roth, cat. no. CE26.1)

-96-well plate incubator (Heidolph Inkubator 1000 and Titramax 1000)

- CD spectrometer (Jasco 715 spectrometer)

- Electroporator (Eppendorf Elektroporator 2510)

- Fluorescence plate reader (Tecan M200)

- Microwave

- PCR cycler (Biometra Thermocycler) 
- Quartz cuvette $(\varnothing 1 \mathrm{~cm})$

- Table-top centrifuge (Eppendorf mini spin)

- UV/Vis photometer (Eppendorf BioPhotomer)

- UV light table (BiodocAnalyze, Biometra)

REAGENT SETUP

$0.8 \%$ (wt/vol) agarose gels Dissolve $0.8 \mathrm{~g}$ agarose in $100 \mathrm{ml} 0.5 \times \mathrm{TBE}$ buffer by boiling in a microwave. Pour the gel in a suitable gel tray and add an appropriate gel comb. Dissolved agarose can be stored in an incubator at $>65^{\circ} \mathrm{C}$ for several days. CRITICAL For purification of the PCR product, it is recommended to use a bigger well (up to $5 \mathrm{~cm}$ ) to prevent overloading of gel in combination with a normal sized well for the DNA marker.

$10 \times \mathrm{CD}$ buffer $500 \mathrm{mM}$ Tris- $\mathrm{HCl}, \mathrm{pH}=7.5,1 \mathrm{M} \mathrm{KCl}$. Dissolve $500 \mathrm{mM}$ Tris- $\mathrm{HCl}$ and $1 \mathrm{M} \mathrm{KCl}$ in ddH ${ }_{2} \mathrm{O}$. Subsequently, adjust $\mathrm{pH}$ to 7.5. Buffer can be stored at $4{ }^{\circ} \mathrm{C}$ for weeks.

$1,000 \times$ carbenicilline stock solution Dissolve $100 \mathrm{mg} \mathrm{ml}^{-1}$ carbenicilline in $50 \%(\mathrm{vol} / \mathrm{vol})$ ethanol. Store in the freezer for several weeks.

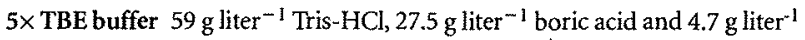
EDTA. Dissolve $20 \mathrm{~g} \mathrm{liter}^{-1}$ tryptone, $5 \mathrm{~g} \mathrm{liter}^{-1}$ boric acid and $4.7 \mathrm{~g} \mathrm{liter}^{-1}$ EDTA in $\mathrm{ddH}_{2} \mathrm{O}$. Buffer can be kept at room temperature $\left(25^{\circ} \mathrm{C}\right)$ for several days. DEPC-treated water Add $1 \mathrm{ml}$ DEPC to 1 liter $\mathrm{ddH}_{2} \mathrm{O}$; stir overnight and autoclave. Can be kept at room temperature for several months. Electrocompetent E. coli BL21 (DE3) gold Detailed protocol for the production of electrocompetent $E$. coli can be found at http://www. eppendorf.com, Protocol No. 4308915.51 . Store at $-80^{\circ} \mathrm{C}$ for several months Ethidium bromide solution Add $200 \mu \mathrm{g}$ ethidium bromide to $400 \mathrm{ml} \mathrm{H}_{2} \mathrm{O}$. Can be kept at room temperature and re-used several times. I CAUTION Ethidium bromide is toxic and mutagenic. Wear nitrile gloves during the work with ethidium bromide all the time.

LB-agar plates Dissolve $20 \mathrm{~g} \mathrm{liter}^{-1} \mathrm{LB}$ medium and $10 \mathrm{~g} \mathrm{liter}^{-1}$ agar in 1 liter $\mathrm{H}_{2} \mathrm{O}$. Add a magnetic stir bar and autoclave. CRITICAL Let the medium cool down to $\sim 50^{\circ} \mathrm{C}$ before adding $1 \mathrm{ml} 1000 \times$ carbenicilline stock solution and stir gently for $5 \mathrm{~min}$. Subsequently, pour the plates in $15 \mathrm{~mm}$ petri dishes. Bubbles can be removed by spraying $70 \%$ (vol/vol) ethanol over the plates. The plates should be stored at $4^{\circ} \mathrm{C}$ for not longer than 6 weeks.
LB-medium Dissolve $20 \mathrm{~g} \mathrm{liter}^{-1} \mathrm{LB}$ medium in 11 liter $\mathrm{H}_{2} \mathrm{O}$, add a magnetic stir bar and autoclave. After cool down, add $1 \mathrm{ml} 1000 \times$ carbenicilline stock solution and stir for $5 \mathrm{~min}$. Store at $4^{\circ} \mathrm{C}$ for several weeks; after addition of the antibiotic it should be stored at $4^{\circ} \mathrm{C}$ for not longer than 1 week.

SOC medium Dissolve $20 \mathrm{~g} \mathrm{liter}^{-1}$ tryptone, $5 \mathrm{~g} \mathrm{liter}^{-1}$ yeast extract, $10 \mathrm{mM} \mathrm{NaCl}, 2.5 \mathrm{mM} \mathrm{KCl}, 10 \mathrm{mM} \mathrm{MgCl}_{2}, 10 \mathrm{mM} \mathrm{MgSO}_{4}$ and $20 \mathrm{mM}$ glucose $\mathrm{ddH}_{2} \mathrm{O}$. Autoclave before use. Medium can be stored at $-20^{\circ} \mathrm{C}$ for several months.

\section{EQUIPMENT SETUP}

PCR-cycler program

\begin{tabular}{lllcl}
\hline Step & Stage & ${ }^{\circ} \mathrm{C}$ & Time & \\
\hline 1 & Initial denaturing & 98 & $30 \mathrm{~s}$ & \\
2 & Denaturing $\times 25$ & 98 & $10 \mathrm{~s}$ & \\
3 & Annealing $\times 25$ & 58 & $30 \mathrm{~s}$ & $\times 24$ \\
4 & Extension $\times 25$ & 72 & $15-30 \mathrm{~s} \mathrm{~kb}^{-1}$ & \\
5 & Final extension & 72 & $7 \mathrm{~min}$ & \\
\hline
\end{tabular}

Cycle steps 2-4 25 times in total.

CRITICAL An annealing temperature of $58^{\circ} \mathrm{C}$ for primers with a binding region $\geq 20$ nucleotides usually works well. However, it is advisable to carry out a gradient PCR testing at annealing temperatures between 55 and $72^{\circ} \mathrm{C}$ in order to achieve highest purity of the desired product.

Eppendorf elektroporator Voltage $=1,800 \mathrm{~V}$, Time constant $(\tau)=5 \mathrm{~ms}$. CD spectrometer (Jasco 715 spectrometer) Circular dichroism spectrum: $\lambda=320-220 \mathrm{~nm}$, resolution: $0.5 \mathrm{~nm}$, band-width: $1.0 \mathrm{~nm}$, sensitivity: 50 mdeg, response: $8 \mathrm{~s}$, speed: $20 \mathrm{~nm} \mathrm{~min}^{-1}$, accumulations: 5 times and temperature: $25^{\circ} \mathrm{C}$. Circular dichroism melting curves: $\lambda=263 \mathrm{~nm}$.

CRITICAL Appropriate wavelength for other structures than G-quadruplexes, heat sample from 20 to $90^{\circ} \mathrm{C}$, heating rate: $1{ }^{\circ} \mathrm{C} \mathrm{min}^{-1}$, record $C D$ signal every $1^{\circ} \mathrm{C}$.

\section{PROCEDURE}

\section{Cloning TIMING $7 \mathrm{~h}$}

1) Set up PCR reaction on ice as described below, aliquot PCR reaction into four PCR tubes and start PCR cycler with the protocol described in EQUIPMENT SETUP:

\begin{tabular}{llcc}
\hline Starting concentration & Component & $\mu$ to add & Final concentration \\
\hline $5 \times$ & HF Buffer & 30 & $1 \times$ \\
$2 \mathrm{mM}$ & dNTP mix & 15 & $200 \mu \mathrm{M}$ \\
$100 \mu \mathrm{M}$ & Forward primer & 0.9 & $600 \mathrm{nM}$ \\
$100 \mu \mathrm{M}$ & Reverse primer & 0.9 & $600 \mathrm{nM}$ \\
$20 \mathrm{ng} \mathrm{Il}^{-1}$ & Template & 1.5 & $30 \mathrm{ng}$ \\
$100 \%(\mathrm{vol} / \mathrm{vol})$ & DMSO & 4.5 & $3 \%(\mathrm{vol} / \mathrm{vol})$ \\
$2 \mathrm{U} \mu \mathrm{l}^{-1}$ & Phusion Hot Start DNA polymerase & 1.5 & $3 \mathrm{U}$ \\
& MilliQ $\mathrm{H}_{2} 0$ & 95.7 & \\
& Total & 150 & \\
\hline
\end{tabular}

A CRITICAL STEP Instead of using Phusion Hot Start DNA polymerase, it is also possible to start PCR without DNA polymerase and add Phusion DNA polymerase when sample temperature has reached $95^{\circ} \mathrm{C}$. Mix well after adding the DNA polymerase.

2) Pool the PCR reaction aliquots in one $1.5-\mathrm{ml}$ Eppendorf tube. Add $16 \mu \mathrm{l}$ of $3 \mathrm{M} \mathrm{Na}$-acetate, $\mathrm{pH} 5.2$ and $480 \mu \mathrm{l} 100 \%$ ( vol/vol) ethanol. Mix by inverting.

3) Put samples in $-80^{\circ} \mathrm{C}$ freezer for at least $15 \mathrm{~min}$ (or $-20^{\circ} \mathrm{C}$ freezer for at least $2 \mathrm{~h}$ ). 


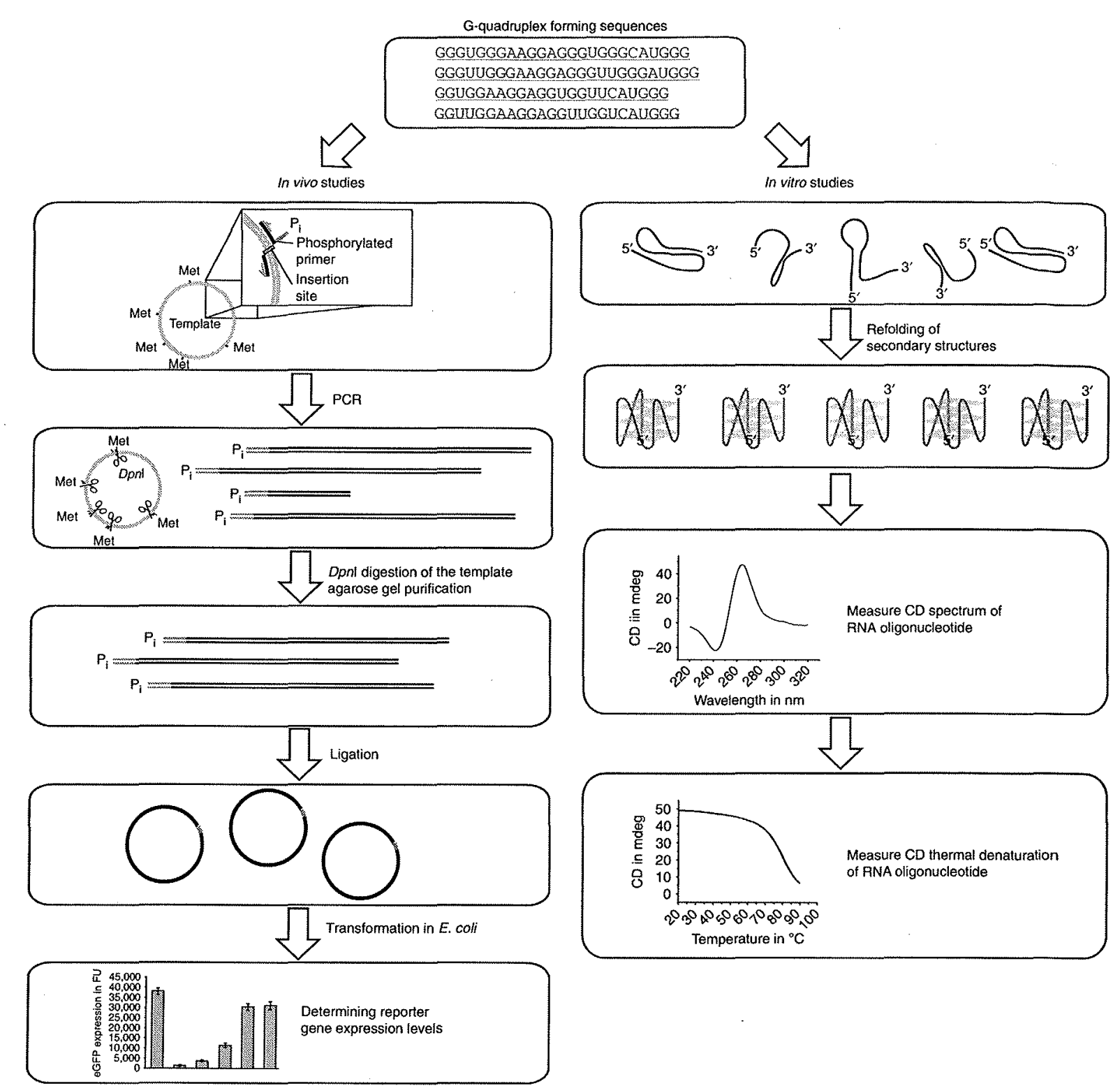

Figure 3 | Ovenview of the protocol. In vivo studies: cloning a G-quadruplex in the mRNA of an enhanced green fluorescent protein (eGFP). G-quadruplex is inserted site specific in the plasmid by a PCR using primers with the G-quadruplex sequence in a 5 '-overhang (in red). Subsequent to PCR, the template is removed by OpnI digestion. After gel purification, the PCR product is ligated and transformed into Escherichia coli, where expression levels of the reporter gene can be determined. In vitro studies: The synthetic RNA oligonucleotides are refolded by heating followed by slowly cooling down. Subsequently the secondary structure of the oligonucleotide is characterized by measuring its circular dichroism $(C D)$ spectrum and $C D$ thermal denaturation.

4| Centrifuge samples in a table-top centrifuge at $\geq 10,000 \mathrm{~g}$ for $15 \mathrm{~min}$ at room temperature $\left(25^{\circ} \mathrm{C}\right)$.

5) A white pellet should be visible at the bottom of the tube. Discard the supernatant carefully by pipetting.

6) Dissolve the pellet in $44 \mu \mathrm{l} \mathrm{H}_{2} \mathrm{O}$. Add $5 \mu \mathrm{L}$ NEB buffer 4 and $1 \mu \mathrm{l}$ DpnI. Mix by pipetting.

7| Digest template by incubating the sample at $37^{\circ} \mathrm{C}$ for $50 \mathrm{~min}$.

8) Prepare $0.8 \%$ (wt/vol) TBE-agarose gel (see REAGENT SETUP). Wait for $15 \mathrm{~min}$ until the agarose has solidified, then put the gel in $0.5 \times$ TBE for $15 \mathrm{~min}$. 
9| Heat-inactivate restriction enzyme by heating the sample (from Step 7) to $80^{\circ} \mathrm{C}$ for $10 \mathrm{~min}$.

10| Add $10 \mu l$ of $6 \times$ NEB agarose gel loading buffer to the sample and mix.

11| Load sample on $0.8 \%$ (wt/vol) TBE-agarose gel (from Step 8) in a long well $(\sim 5 \mathrm{~cm}$ ). Load $2.5 \mu$ l GeneRuler $1 \mathrm{~kb}$ DNA ladder, ready-to-use, in normal well $(\sim 0.5 \mathrm{~cm})$.

12| Run the agarose gel at $10 \mathrm{~V} \mathrm{~cm}^{-1}$ (distance between the electrodes) for $75 \mathrm{~min}$.

13| Allow DNA to be visualized in the agarose gel by placing the gel in ethidium bromide solution for 15 min.

I CAUTION Ethidium bromide is toxic and mutagenic. Wear nitrile gloves all the time while working with ethidium bromide. ? TROUBLESHOOTING

14) Visualize DNA by observing the gel under UV light.

CRITICAL STEP UV light $(\sim 236 \mathrm{~nm})$ visualizes ethidium bromide bound to dsDNA. However, strong UV light also quickly degrades DNA. It is recommended to cut off a small part of the gel containing the DNA ladder and a small portion of the PCR product. Put this small part of the gel on a UV light table and cut out the DNA band in the appropriate size. Reunite the pieces of the agarose gel on a plastic tray and cut out the rest of the PCR product using the small gel piece as a size ruler (see Fig. 4). As an alternative to the UV irradiation, the gel can be stained with SYBR Green and subsequently visualized by a blue lamp.

15| Purify DNA from agarose using Zymoclean Gel DNA Recovery kit; add 3 volumes of ADB buffer and incubate at $55^{\circ} \mathrm{C}$ until the agarose has dissolved. Load $750 \mu \mathrm{l}$ of dissolved agarose on the provided column, centrifuge in table-top centrifuge at $\geq 10,000 \mathrm{~g}$ for $15 \mathrm{~s}$ at room temperature $\left(25^{\circ} \mathrm{C}\right)$. Discard flowthrough and repeat till agarose is used up. Add $200 \mu \mathrm{l}$ wash buffer and centrifuge at $\geq 10,000 \mathrm{~g}$ for $15 \mathrm{~s}$ at room temperature, then repeat this wash. Discard flowthrough and centrifuge at $\geq 10,000 \mathrm{~g}$ for $60 \mathrm{~s}$ at room temperature to remove residual ethanol. Elute DNA in $15 \mu \mathrm{l} \mathrm{H} 20$.

16| Dilute $5 \mu \mathrm{l}$ sample with $45 \mu \mathrm{l} \mathrm{H}_{2} 0$. Meassure $E_{260}$ in a UV/Vis photometer and calculate sample concentration using the following equation:

$$
c=E_{260} \times 50 \mathrm{ng} \mu^{-1} \times 10 \text { (dilution factor) }
$$

17) Combine $30 \mathrm{ng}$ of purified PCR product in a total volume of $9 \mu \mathrm{l}$ with $10 \mu \mathrm{l} 2 \times$ Quick Ligation buffer. Add $1 \mu \mathrm{l}$ Quick Ligase (NEB) and mix well.

18| Incubate at $25^{\circ} \mathrm{C}$ for $15 \mathrm{~min}$.

19| Purify sample using a Zymo.DNA Clean \& Concentrator; add 40- $\mu$ LNA binding buffer to the sample and mix. Transfer sample to a column a centrifuge at $\geq 10,000 \mathrm{~g}$ for $15 \mathrm{~s}$ at room temperature $\left(25^{\circ} \mathrm{C}\right)$. Add $200 \mu \mathrm{l}$ wash buffer and centrifuge at $\geq 10,000 \mathrm{~g}$ for $15 \mathrm{~s}$ at room temperature, then repeat this wash. Discard flowthrough and centrifuge at $\geq 10,000 \mathrm{~g}$ for $60 \mathrm{~s}$ at room temperature to remove residual ethanol. Elute DNA in $7 \mathrm{HL} \mathrm{H}_{2} \mathrm{O}$.

CRITICAL STEP Desalting the sample is very important for electroporation in order to avoid short-circuit. However, if performing a heat-shock transformation instead, purification of ligation mix might not be necessary.

20| Thaw electro-competent $E$. coli BL21 (DE3) gold cells on ice.

21) Chill electroporation cuvette on ice for $10 \mathrm{~min}$.

Figure 4 | Excision of DNA from agarose gel without UV irradiation. Small part of the sample including the DNA size marker is cut off from the gel and put on a UV light table (hatched area). DNA band with the appropriate size is cut out and then the pieces of the agarose gel are reunited on a plastic tray. The rest of the PCR product can be cut out using the small gel piece as a size ruler. This way the main part of the sample is not exposed to damaging UV light.

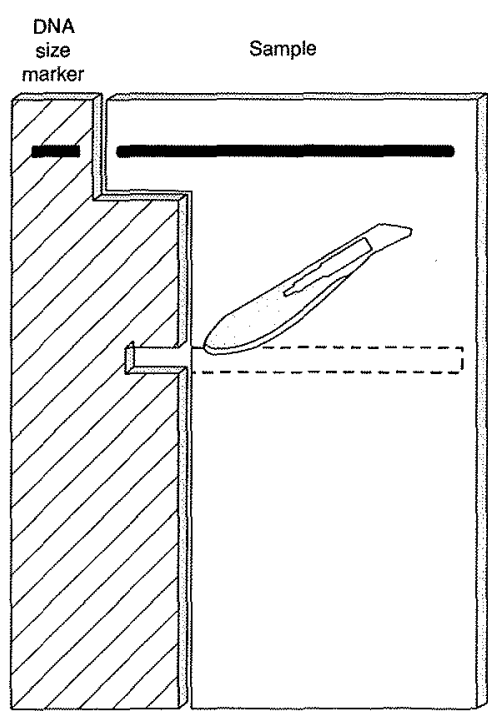


22) Preheat $1 \mathrm{ml} \mathrm{SOC}$ medium at $37^{\circ} \mathrm{C}$ for $10 \mathrm{~min}$.

23| Add $1.5 \mu$ l of the purified sample to $80 \mu \mathrm{l}$ competent cells and mix carefully.

$24 \mid$ Transfer the competent cells into a pre-chilled electroporation cuvette. Snap with finger against cuvette to remove possible air bubbles.

25| Put cuvette into Electroporator and transform cells (as described in EQUIPMENT SETUP).

26| Rinse the transformed cells out of the cuvette using $900 \mu \mathrm{l}$ warm SOC medium and transfer to a $1.5 \mathrm{ml}$ Eppendorf tube.

27| Incubate transformed cells at $37^{\circ} \mathrm{C}$ for $1 \mathrm{~h}$.

CRITICAL STEP If using ampicillin resistance, incubation is not necessary and cells can be plated immediately.

28| Plate $100 \mu \mathrm{l}$ transformed cells on a preheated LB-carbenicillin plate.

29| Incubate at $37^{\circ} \mathrm{C}$ overnight.

30 ㅇ Use a sterile toothpick (or pipette tip) to pick a single colony in $10 \mathrm{~mL} \mathrm{LB}$-carbenicilline medium.

? TROUBLESHOOTING

31) Incubate by vigorously shaking at $37^{\circ} \mathrm{C}$ for at least $6 \mathrm{~h}$.

32| Isolate plasmid from liquid culture using any Miniprep kit.

33| Check for successful cloning by sequencing.

\section{? TROUBLESHOOTING}

eGFP measurement TIMING $1 \mathrm{~d}$

34| Transfer $1 \mathrm{ml} \mathrm{LB}$-carbeniciltin medium to as many wells of a 96-deep well plate as needed.

35| Inoculate six wells for every clone to be measured with $30 \mu$ lovernight culture of a sequenced clone.

CRITICAL STEP Inoculate cells harbouring an empty vector not expressing eGFP as a background control and the wild-type (wt)-vector for wt control of expression level.

36| Incubate at $37^{\circ} \mathrm{C}$ on a plate incubator for at least $24 \mathrm{~h}$.

CRITICAL STEP EGFP maturation takes some hours. Although cells are outgrown eGFP fluorescence levels can still be rising over time. To achieve comparable results wait till eGFP level is not changing anymore (see Fig. 5).

37| Transfer (with a multi-channel pipette) $100 \mu \mathrm{l}$ of culture into a black 96 -well plate.

38| Measure eGFP expression levels by measuring fluorescence of culture with excitation wavelength $\lambda_{\text {ex }}=488 \mathrm{~nm}$ and emission wavelength $\lambda_{\text {em }}=535 \mathrm{~nm}$.

? TROUBLESHOOTING

CD spectrum TIMING $15 \mathrm{~h}+5 \mathrm{~h}$ per sequence

39| Order RNA oligonucleotides HPLC purified or synthesize according to reference 25 and references therein.

CRITICAL STEP Always use DEPC-treated water and wear gloves while working with RNA.

40 이 Measure the concentration of ordered RNA; determine $E_{260}$ in a UV/Vis photometer and calculate the extinction coefficient $\varepsilon$ with this tool: http://eu.idtdna.com/analyzer/ Applications/OligoAnalyzer/.

Figure 5 | Growth curve of Escherichia coli and enhanced green fluorescent protein (eGFP) expression of the same culture grown in LB-carbenicilline medium. Black square: Absorbance of culture at $600 \mathrm{~nm}$, red circles: eGFP expression.

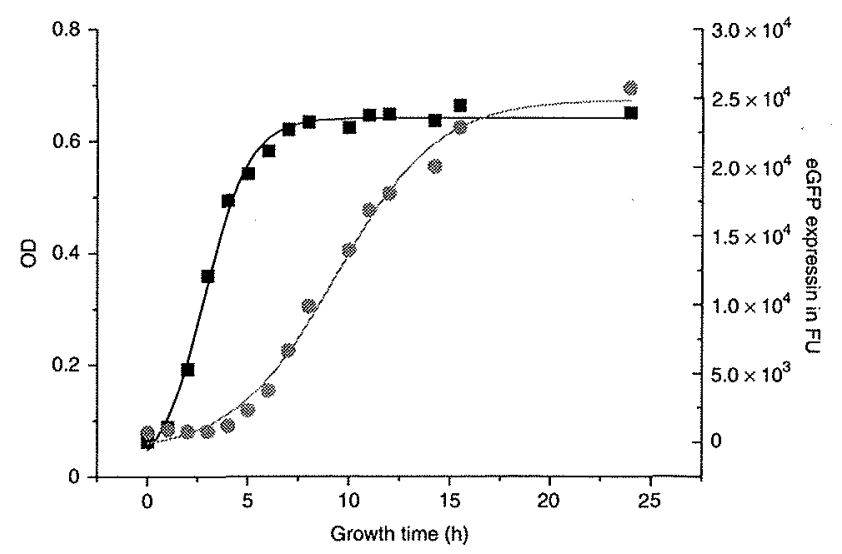


Calculate the RNA sample concentration with the following equation: $c=E_{260} \times \varepsilon^{-1}$

41) Dilute 2.5-nmol RNA sample in a total volume of 450- $\mu \mathrm{l} \mathrm{H}_{2} \mathrm{O}$. Add $50 \mu \mathrm{l}$ of $10 \times \mathrm{CD}$ buffer to achieve a final concentration

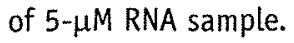

42| Aliquot the RNA sample into ten lots of $50 \mu \mathrm{l}$ in PCR tubes.

43| Start refolding of secondary structure by heating to $95^{\circ} \mathrm{C}$ for 5 min followed by slow cool down to $20^{\circ} \mathrm{C}$ $\left(0.08^{\circ} \mathrm{C} \mathrm{min}^{-1}\right)$ in a PCR cycler.

44| Transfer refolded RNA sample to a Quartz cuvette and close cuvette with a tight plug to prevent evaporation.

\section{觟 TIMING $1 \mathrm{~h}$}

45| Measure CD spectrum (as described in EQUIPMENT SETUP).

\section{? TROUBLESHOOTING}

\section{弱 TIMING $4 \mathrm{~h}$}

46| Measure CD melting curve (as described in EQUIPMENT SETUP).

\section{$?$ TROUBLESHOOTING}

47| Calculate the melting point of secondary structure by determining the temperature at half-maximum decrease of the signal.

\section{TIMING}

Steps 1-33, Cloning: $7 \mathrm{~h}$

Steps 34-38, eGFP measurement: $1 \mathrm{~d}$

Steps 39-44, CD spectrum: $15 \mathrm{~h}$

Step 45, CD spectrum: $1 \mathrm{~h}$

Step 46 , CD melting curve: $4 \mathrm{~h}$

\section{? TROUBLESHOOTING}

Troubleshooting advice can be found in Table 1.

TABLE 1 | Troubleshooting table.

\begin{tabular}{llll}
\hline Step & Problem & Possible reason & Solution \\
\hline 13 & No/wrong PCR product & $\begin{array}{l}\text { Primers do not bind/bind } \\
\text { non-specifically }\end{array}$ & $\begin{array}{l}\text { Carry out gradient PCR for optimized annealing } \\
\text { temperature }\end{array}$ \\
30 & No colonies visible on plate & Primer is not phosphorylated & Phosphorylate primer with T4 polynucleotide kinase \\
33 & $\begin{array}{l}\text { Sequencing reveals unwanted } \\
\text { insertion/deletion mutants } \\
\text { eGFP expression data is }\end{array}$ & Primer quality is not sufficient & $\begin{array}{l}\text { Use a denaturing PAGE gel for additional primer } \\
\text { purification }\end{array}$ \\
not consistent & eGFP expression level did not & Incubate cell for at least 15 $\mathrm{h}$ (see Fig. 5) \\
No CD signal & reach stationary phase & RNA is degraded & $\begin{array}{l}\text { Follow common rules for working with RNA. For } \\
\text { detailed instruction, see reference 26 }\end{array}$ \\
\hline
\end{tabular}

CD, circular dichroism; eGFP, enhanced green fluorescent protein; PAGE, polyacrylamide gel electrophoresis.

\section{ANTICIPATED RESULTS}

Insertion of stable G-quadruplex structures around the SD sequence should result in reduced gene expression levels (see Fig. 2c). If no other (protein) factors are involved, the gene expression reduction should be inversely correlating with the thermodynamic stability of the inserted G-quadruplex. This should also apply to secondary structures other than G-quadruplexes. Whether the investigated sequence forms a quadruplex should be investigated by CD spectroscopy. A CD spectrum for an RNA G-quadruplex shows a maximum at $263 \mathrm{~nm}$ and a minimum at $240 \mathrm{~nm}$ (see Fig. 2d inset). RNA quadruplex sequences typically fold into parallel topologies exclusively. $C D$ melting curves are usually recorded at a wavelength corresponding to the maximum or minimum of the CD spectrum $(263$ or $240 \mathrm{~nm}$ ). Usually the CD signal decreases (if recorded at $263 \mathrm{~nm}$ ) or increases $(240 \mathrm{~nm}$ ) in a temperature-dependent manner to 0 mdeg (see Fig. $2 \mathrm{~d}$ ). The melting point corresponds to the halfmaximum of the decrease (increase) of the signal. However, it is not possible to obtain a CD melting curve of secondary struc- 
tures with a melting point greater than $90^{\circ} \mathrm{C}$ (e.g., $\left(\mathrm{G}_{3} \mathrm{U}\right)_{3} \mathrm{G}$ in buffers containing high concentrations of $\mathrm{Na}^{+}$or $\left.\mathrm{K}^{+}\right)$.

ACKNOWLEDGMENTS J.S.H. gratefully acknowledges the VolkswagenStiftung for funding a Lichtenberg-Professorship, the Fonds der chemischen Industrie and the University of Konstanz for financial support. We thank A. Joachimi for excellent technical assistance.

\section{AUTHOR CONTRIBUTIONS All authors contributed equally to this work.}

Published online at http://www.natureprotocols,com Reprints and permissions information is available online at http://npg. nature.com/ reprintsandpermissions.

1. Patel, D.J., Phan, A.T. \& Kuryavyi, V. Human telomere, oncogenic promoter and 5'-UTR G-quadruplexes: diverse higher order DNA and RNA targets for cancer therapeutics. Nucleic Acids Res. (2007)

2. Burge, S., Parkinson, G.N., Hazel, P., Todd, A.K. \& Neidle, S. Quadruplex DNA: sequence, topology and structure. Nucleic Acids Res. 34, 5402-5415 (2006).

3. Siddiqui-Jain, A., Grand, C.L., Bearss, D.J. \& Hurley, L.H. Direct evidence for a $\mathrm{G}$-quadruplex in a promoter region and its targeting with a small molecule to repress C-MYC transcription. Proc. Natl. Acad. Sci. USA 99, 11593-11598 (2002).

4. Paeschke, K., Simonsson, T, Postberg, J., Rhodes, D. \& Lipps, H.J. Telomere end-binding proteins control the formation of G-quadruplex DNA structures in vivo. Nat. Struct. Mol. Biol. 12, 847-854 (2005).

5. Du, Z., Zhao, Y. \& Li, N. Genome-wide analysis reveals regulatory role of G4 DNA in gene transcription. Genome Res. 18, 233-241 (2008).

6. Rawal, P. et al. Genome-wide prediction of G4 DNA as regulatory motifs: role in Escherichia coli global regulation. Genome Res. 16, 644-655 (2006)

7. Schaffitzel, C. et al. In vitro generated antibodies specific for telomeric guanine-quadruplex DNA react with Stylonychia lemnae macronudei. Proc. Natl. Acad. Sci. USA 98, 8572-8577 (2001)

8. Ji, L., Arcinas, M. \& Boxer, L.M. The transcription factor, Nm23H2, binds to and activates the translocated c-myc allele in Burkitt's lymphoma. J. Biol. Chem. 270, 13392-13398 (1995).

9. Tang, C.F. \& Shafer, R.H. Engineering the quadruplex fold: nucleoside conformation determines both folding topology and molecularity in guanine quadruplexes. J. Am. Chem. Soc. 128, 5966-5973 (2006).

10. Arora, A. et al. Inhibition of translation in living eukaryotic cells by an RNA G-quadruplex motif. RNA 14, 1290-1296 (2008).
11. Kumari, S., Bugaut, A., Huppert, J.L. \& Balasubramanian, S. An RNA Gquadruplex in the $5^{\prime}$ UTR of the NRAS proto-oncogene modulates translation. Nat. Chem. Biol. 25, 25 (2007).

12. Wang, S., Mortazavi, L. \& White, K.A. Higher-order RNA structura requirements and small molecule induction of tombusvirus subgenomic mRNA transcription. J. Virol. (2008).

13. Wieland, M. \& Hartig, J.S. RNA quadruplex-based modulation of gene expression. Chem. Biol. 14, 757-753 (2007).

14. Wieland, M. \& Hartig, J.S. Improved aptazyme design and in vivo screening enable riboswitching in bacteria. Angew. Chem. Int. Ed. Engl. 47, 2604-2607 (2008)

15. Wieland, M., Gfell, M. \& Hartig, J.S. Expanded hammerhead ribozymes containing addressable three-way junctions. RNA 15, 968-976.

16. Wieland, M., Benz, A., Klauser, B. \& Hartig, 3.S. Artificial ribozyme switches containing natural riboswitch aptamer domains. Angew. Chem Int. Ed. Engl. 48, 2715-2718 (2009).

17. Shine, J. \& Dalgarno, L. Terminal-sequence analysis of bacterial ribosomal RNA. Correlation between the $3^{\prime}$-terminal-polypyrimidine sequence of $16-5$ RNA and translational specificity of the ribosome. Eur. J. Biochem. 57, 221-230 (1975).

18. Shine, J. \& Dalgarno, L. The 3'-terminal sequence of Escherichia coli 165 ribosomal RNA: complementarity to nonsense triplets and ribosome binding sites. Proc. Natl. Acad. Sci. USA 71, 1342-1346 (1974).

19. Narberhaus, F., Waldminghaus, T. \& Chowdhury, S. RNA thermometers. FEMS Microbiol. Rev, 30, 3-16 (2006).

20. Grundy, F.J. \& Henkin, T.M. From ribosome to riboswitch: control of gene expression in bacteria by RNA structural rearrangements. Crit. Rev. Biochem. Mol. Biol. 41, 329-338 (2006).

21. Hazel, P., Huppert, J., Balasubramanian, S. \& Neidle, S. Loop-lengthdependent folding of G-quadruplexes. J. Am. Chem. Soc. 126, 16405-16415 (2004)

22. Smirnov, I. \& Shafer, R.H. Effect of loop sequence and size on DNA aptamer stability. Biochemistry 39, 1462-1468 (2000)

23. Rachwal, P.A., Brown, T. \& Fox, K.R. Effect of G-tract length on the topology and stability of intramolecular DNA quadruplexes. Biochemistry 46, 3036-3044 (2007)

24. Benz, A. \& Hartig, J.S. Redesigned tetrads with altered hydrogen bonding patterns enable programming of quadruplex topologies. Chem. Commun. (Camb). 4010-4012 (2008).

25. Lang, K. \& Micura, R. The preparation of site-specifically modified riboswitch domains as an example for enzymatic ligation of chemically synthesized RNA fragments. Nat. Protoc. 3, 1457-1466 (2008).

26. Sambrook, J. \& Russell, D. Molecular Cloning 3rd edn. (CSHL Press, New York, 2001) 